\title{
Integrity of edible Nano-coatings and its effects on quality of strawberries subjected to simulated in-transit vibrations
}

\author{
Rajiv Dhital $^{1}$, Prabesh Joshi ${ }^{1}$, Nathalie Becerra ${ }^{2}$, Arosha Umagiliyage ${ }^{1}$, Tan Chai ${ }^{3}$, Punit \\ Kohli $^{2}$, Ruplal Choudhary ${ }^{1^{*}}$ \\ ${ }^{1}$ Department of Plant, Soil and Agricultural Systems, Southern Illinois University, Carbondale. \\ ${ }^{2}$ Department of Chemistry and Biochemistry, Southern Illinois University, Carbondale. \\ ${ }^{3}$ Department of Mechanical Engineering, Southern Illinois University, Carbondale. \\ *Corresponding Author: 1205 Lincoln Drive Room 176, Carbondale IL 62901, USA. Email: \\ choudhry@siu.edu; Phone: 6184536985
}

\begin{abstract}
Strawberries are a popular fruit with a pleasing color and flavor. However, its delicate tissue and high sugar content makes it highly perishable with visible mold. In this study, we have attempted to test feasibility of a new edible coating for extending shelf life of 'Chandler' strawberries subjected to simulated vibrations of local transportation. Six types of coatings were compared based on the quality of treated berries. Curcumin and limonene were used as natural antimicrobials and coatings were prepared from their liposomes and were over-coated with methyl cellulose. One set of each coating type were subjected to the simulated vibration of local transportation. The vibrated samples had lower shelf life than non-vibrated samples, indicating a robust coating which remains intact during road vibrations is required. Based on the number of berries with visible mold, limonene liposomes showed significantly lower fungal growth compared to the control on the $14^{\text {th }}$ day of storage. Titratable acidity and total phenolic contents were also found to be higher in limonene coated strawberries compared to other coatings. Further study is suggested to test liposome coatings of limonene with different particle size to improve integrity of the coatings when strawberries are subjected to local transportation.
\end{abstract}

Keywords: Strawberry shelf life; edible coating; simulated local transportation; liposome; limonene; curcumin.

\section{Introduction}


Strawberries (Fragaria $x$ ananassa) are a high demand fruit because of their pleasant aroma, brilliant color, and delicious taste. They are also a good source of natural antioxidants, vitamins, minerals and a significant amount of anthocyanins, flavonoids and phenolics (Rice-Evans and Miller 1996, Heinonen, Meyer et al. 1998). The berries are harvested at full maturity in order to maintain sensory (visual appearance, firmness, color) and nutritional (phytonutrients, minerals and vitamins) qualities (Hernandez-Munoz, Almenar et al. 2008). One of the most important quality indicators in strawberries is the sugar to acid ratio, which characterizes degree of sweetness and depends on the maturity, cultivar and weather conditions of berries (Pineli, Moretti et al. 2011, Hu et al. 2012). Sugar to acid ratio in matured strawberries varies with the variety, usually within a range from 7:1 for fruits regarded as sweet and 6:1 for fruits regarded as acidic in taste (Wozniak et al. 1996). Due to its high respiration rate, soft texture and sensitivity to temperature and mechanical shocks and vibrations, strawberries have postharvest shelf life shorter than 1 week under ideal conditions at $0{ }^{\circ} \mathrm{C}$. This results in high degree of perishability to several pathogens, which would in turn cause changes in $\mathrm{pH}$, titratable acidity, total soluble solids (TSS), loss in color, firmness and weight resulting in spoilage and, shortening the shelf life.

Several attempts have been made to increase the postharvest quality of fruits and vegetables. The most common method for maintaining quality and preventing decay is the use of low temperatures under refrigeration (Han and Nie 2004, Hernandez-Munoz, Almenar et al. 2006). Similarly, use of low temperatures and modified atmospheric packaging (MAP) in combination with increased concentration of carbon dioxide (Manning 1993) and paraffin-based active coatings by the use of essential oils for paper packaging of fruits and vegetables (Rodriguez et al., 2007) are also in practice. These strategies, however, are expensive, time consuming, and cause change in visual appearance of fruits and develop off-flavor in fruits (Ke, Zhou et al. 1994). The need of alternative methods to minimize the risk of undesirable biological, physiochemical, and physiological changes of fruits and vegetables is desirable (Holcroft and Kader 1999). 
There has been an increasing trend in use of natural bioactive edible coatings composed of polysaccharides, proteins, lipids, resins or of various composites in post-harvest preservation of fruits and vegetables (Valencia-Chamorro, Perez-Gago et al. 2010). Edible coatings such carnauba wax, whey proteins, gluten, shellac coatings, mucilage starch have exhibited beneficial roles in maintaining quality of fruits and vegetables (Raghav et al., 2016). Apart from protection of products from mechanical and microbiological damage to the fruits, these compounds have shown to preserve post-harvest quality of fruits by preventing the loss of volatile compounds (Perez- Gago, Rojas et al. 2002). These coatings are developed from natural sources and are easily biodegradable, which meets the demand of consumers to have a safer food product (Pavlath and Orts 2009). These coatings are of interest as coating materials due to their low-cost, biodegradability, and solubility in water (Debeaufort, Quezada-Gallo et al. 1998).

Researchers have demonstrated that the use of plant based essential oils and phenolic compounds as coating materials can be done in order to increase the shelf life, prevent microbial growth, and to prevent nutrients loss from foods (Salmieri and Lacroix 2006). These compounds have shown strong antimicrobial and antifungal properties, which makes them a natural alternative for the prevention of pathogenic and spoilage organisms that may occur in foods (Lacroix 2007).

Limonene ((R)-(+)-para-Mentha-1,8-diene) is an essential oil extracted from lemon peels and other citrus fruits (Moufida and Marzouk 2003). It is commonly used as a food additive or flavoring agent and has a Generally Recognized as Safe (GRAS) status by US Food and Drug Administration (EPA 1994). Similarly, it has exhibited fungicidal activities against Botrytis and Asperigillus niger, the most common spoilage causing molds for fruit (Sharma and Tripathi 2008). A natural phenylpropanoid dimer Curcumin (1,7-bis(4-hydroxy-3-methoxyphenyl)-1,6heptadiene-3,5-dione) is the principle curcuminoid of turmeric Curcuma longa L. which is used as a spice and traditional medicine in various parts of South and East Asia (Dogra, Choudhary et al. 2015). Several studies suggest curcumin to be an effective anti-proliferative, anti-oxidant and anti-inflammatory agent (Maheshwari, Singh et al. 2006). Like limonene, curcumin is also considered as "Generally Recognized as Safe" for application in food and pharmaceutical formulations by US Food and Drug Administration. 
Although having many food preservation qualities, the use of essential oils in food preservation is limited due to certain drawbacks. These include high costs and potential toxicity to the consumers. An approach to address these demerits while maintaining the efficacy of essential oils and decreasing their dose would be the incorporation of these chemicals in a formulation of edible coatings (Perdones, Escriche et al. 2016). A study by Sanchez-Gonzalez et al. (2011), in development of an antibacterial composite films of Hydroxypropylmethyl cellulose (HPMC) and chitosan mixed with different essential oils (Lemon, tea tree and bergamot) showed that the antibacterial activity of chitosan was enhanced when it was used with a mixture of the polymer and essential oil. Similarly, chitosan films incorporated with essential oils inhibited growth of the Gram negative and positive bacteria Escherichia coli, Listeria monocytogenes and Staphylococcus aureus.

Application of nanomaterials have shown to have a potential impact in a wide range of industries (Michael 2004, Wang, Liang et al. 2004). In food industries too, the application of nanotechnology to enhance the quality of fruits has been used extensively (Yang, Li et al. 2010). Fruits and vegetables with nano-packing have shown better physiochemical, sensory physiological and preservation properties compared with normal packaging (Huang and $\mathrm{Hu}$ 2006, Li and Wang 2006, Li, Li et al. 2009). Liposomes are amphiphilic vesicles containing polar heads and hydrophobic carbon tails basically designed by dispersal of phospholipids in water (Bangham 1961). They can transport hydrophilic components by encapsulation in aqueous phase and hydrophobic components in stable state by inserting into hydrophobic domains (Brandl 2001, Shin, Chung et al. 2013). Size of the liposomes can be controlled to the order of nanometers, providing desirable properties to deliver essential chemicals of hydrophilic and hydrophobic nature. Their application in food preservation includes the encapsulation of nutrients, proteins, enzymes, antimicrobials and flavors and controlled release in the food environment to maintain food quality and prevent microbial spoilage (Makwana, Choudhary et al. 2015).

Mechanical injuries during transportations of fruits and vegetables between the chain of harvesting and consumption are one of the major causes of decay of fruits and vegetables (Barchi, Berardinelli et al. 2002). Strawberries are highly prone to in-transit vibration damage 
causing skin abrasion and bruising. From these abrasions and bruises on the tissues of berries, microbes are able to enter inside which in turn causes the degradation of berries and reduce the shelf life (Fischer, Craig et al. 1992). Significant losses due to damage caused by in-transit vibration has been recorded in strawberries (Pierson, Allen et al. 1982).

In this study, fresh ripened berries were picked up from the local farms in Southern Illinois. The berries were stored in a cold room at $4^{\circ} \mathrm{C}$ before any treatment and processing was done. Since the phenolic compounds, vitamin $\mathrm{B}$ and vitamin $\mathrm{C}$ are sensitive to the higher storage temperatures; refrigerated temperature at $4{ }^{\circ} \mathrm{C}$ is considered as safe level for storage.

The berries were treated with various types of natural coatings and subjected to simulated shock and vibration. The effect of different natural edible coating formulations on shelf life of strawberries was compared. The effects of mechanical shocks and vibrations of simulated road transport on the quality of berries were analyzed. Physiochemical and nutritional quality of treated berries were evaluated by the measurement of visible mold growth, total soluble solids, $\mathrm{pH}$, titratable acidity, and total phenolic content at different time intervals.

\section{Materials and Methods}

Fresh ripened strawberries 'Chandler' were purchased from local farms located in southern Illinois. The berries were inspected for bruises, visual fungal growth, and decay. Uniform sized berries were selected and stored at $4^{\circ} \mathrm{C}$ prior to coating and mechanical vibration experiments. Steps for preparation of coating materials are shown in a flowchart form (Figure 8).

\subsection{Preparation of phytochemical solutions}

Curcumin solution with a concentration of $50 \mathrm{mM}$ was used as a coating material. Powdered curcumin was initially dissolved in 2-3 drops of ethanol. For example, for the preparation of 25 $\mathrm{ml}$ curcumin solution with concentration of $50 \mathrm{mM}, 0.00046 \mathrm{gm}$ curcumin powder was weighed and dissolved in ethanol followed by addition of $25 \mathrm{ml}$ nano pure water. 
Similarly, for the preparation of $25 \mathrm{ml}$ limonene solution with the concentration of $50 \mathrm{mM}$ $0.01703 \mathrm{ml}$ D-limonene was poured in a volumetric flask and desired volume was made by pouring $25 \mathrm{ml}$ Nano- pure water.

\subsection{Preparation of Methyl cellulose solution}

Methyl cellulose solution at a concentration of $1.5 \%(1.5 \mathrm{gm}$ in $100 \mathrm{ml})$ was used as a coating material. Initially, powdered Methyl cellulose was dissolved in warm water at a temperature around $50^{\circ} \mathrm{C}$ for the complete dissolution. Then, followed by addition of Nano-pure water to make up the desired volume.

\subsection{Preparation of Curcumin and D- Limonene Liposomes}

Thin film dehydration method was used for the preparation of lipid film. Briefly, a mixture of dimyristoylphosphatidylcholine (DMPC), Polydiacetylene (PDA; 10,12-Pentacosadiynoic acid) and N-hydroxysuccinimide (NHS) was dissolved in $25 \mathrm{~mL}$ of dichloromethane in a round bottom flask. The solution was then subjected to rotary evaporation for 1 hour to evaporate the solvent and bilayer film formation. The resulting film was dried overnight by placing the flask on a vacuum pump. The film was then hydrated by the addition of $50 \mathrm{mM}$ concentration of phytochemicals (Curcumin or d-limonene) prepared in Nano-pure water. The resulting solution was then left for sonication for 20 minutes for the complete detachment of the film. Further, the solution was placed in a probe sonicator (VCX 500, Vibra-cell, Newtown, CT) at $76^{\circ} \mathrm{C}$ for 15 minutes to produce small vesicles with diameter less than $110 \mathrm{~nm}$. The solution was then filtered through $0.45 \mu \mathrm{m}$ nylon fiber to remove the lipid aggregates. Thus obtained liposomes were collected in a vial and covered with aluminum foil. Liposomes were polymerized by irradiation with a UV lamp emitting at $254 \mathrm{~nm}$ for approximately 2-5 min using a Pen Ray (UVGL-58, Minerallight, Upland, CA) UV source $\left(4.5 \mathrm{~mW} / \mathrm{cm}^{2}\right)$ in air. The polymerized liposome solution was transferred into a dialysis membrane and dialysis was done for 48 hours changing the water every 4 hours. The dialyzed liposomes were stored at $4^{\circ} \mathrm{C}$ and stability was observed for 7 days. 
The liposomes were characterized and the results were presented in Dogra et al. (2015). A diagram representing the preparatory steps for the liposomes is given in Figure 9.

\subsection{Application of coating materials}

For each coating material types, six sterile clam shell boxes each containing 20 uniform sized berries were selected. The non-coated sample was used as a control. Two sets of coatings were prepared for the analysis of quality parameters. The first set consists of coatings in which curcumin was used, namely; Curcumin only, Curcumin liposomes, Methyl cellulose, bilayer coating of Curcumin followed by Methyl cellulose and non-coated as control. The second set consists of coatings in which D-limonene was used, namely; D-limonene only, D-Limonene liposomes, Methyl cellulose, bilayer coating of D-Limonene followed by Methyl cellulose and non-coated as control.

Berries were dipped in the solutions of coating materials for 10 minutes, air-dried in a UV sterilized cabinet drier for 1 hour at $20^{\circ} \mathrm{C}$, transferred into clamp shell boxes, and stored at $4^{\circ} \mathrm{C}$. For the coatings in which bilayer of phytochemicals and Methyl cellulose were used, the berries were initially dipped in the phytochemicals for 10 minutes, dried, dipped in Methyl cellulose solution and stored at $4^{\circ} \mathrm{C}$.

\subsection{Vibration tests}

For each coating material, three boxes of coated strawberries were subjected to simulated vibration tests immediately after drying, while the other three boxes were not subjected to vibration tests. The system used to simulate the vibrations during local transportations consists of a vibration shaker (Modal Shop 2060E) with a test platform, a digital signal generator, and an amplifier (Fig. 1). A sweep sine signal controlled by the signal generator and the amplifier was fed to the shaker. Based on the frequency components of the measured vibrations in a truck when 
transporting strawberries locally, each sinusoidal signal was set to sweep from 2 to $80 \mathrm{~Hz}$ at an acceleration level of $0.4 \mathrm{~g}\left(1 \mathrm{~g}=9.8 \mathrm{~m} / \mathrm{s}^{2}\right)$. A piezoelectric accelerometer placed on the test platform and a National Instrument data acquisition system were used to monitor the vibration levels during the test. Each box of strawberry sample was subjected to vibrations for 2 hours at room temperature. The non-vibrated samples were also kept in the same conditions of temperature for 2 hours. The vibrated and non-vibrated strawberries were again stored at $4^{\circ} \mathrm{C}$ after the vibration tests.

2.6. Evaluation of fungal decay on strawberries

The stored strawberries were visually inspected for fungal decay for 14 days at different time intervals $(0,2,5,9$ and 14 days) after coating and vibration tests were performed. Day 0 corresponded to the day of treatment and vibration. Fungal decay percentage on the berries was calculated. Fungal decay percentage is defined as the percentage (\%) of strawberries which showed the visual presence of one or more colonies of molds on their surface during storage to the total number of berries.

\subsection{Total soluble solids (TSSs), Titratable acidity (TA) and $\mathrm{pH}$ determinations}

The quality parameters TSS, TA and $\mathrm{pH}$ of strawberries were measured at different time intervals $(0,2,5,9$ and 14 days). One fruit from each triplicate were taken and wrapped in a sterile cheesecloth and squeezed with hands. The TSSs of the resulting juice were measured at $20^{\circ} \mathrm{C}$ by a Brix refractometer $\left(r^{2}\right.$ mini, Reichert Analytical Instruments, Depew, NY). Similarly, $\mathrm{pH}$ of the juice was measured by a $\mathrm{pH}$ meter (Corning $\mathrm{pH} /$ ion analyzer 350 ). TA was determined by titrating the diluted juice $(5 \mathrm{ml}$ juice diluted in $95 \mathrm{ml}$ distilled water) up to $\mathrm{pH} 8.2$ using $0.1 \mathrm{~N}$ $\mathrm{NaOH}$.

\subsection{Total phenolic compound analysis}

Fruit samples at different days of storage (0,2, 5, 9 and 14 days) after coating and vibration tests were taken. Briefly, a $1.5 \mathrm{~g}$ strawberry sample grinded in a mortar and pestle was weighted and extracted with 20ml mixture of acetone, water and acetic acid (70:29.5:0.5 v/v). The samples 
were vortexed for 1 hour at room temperature for complete extraction, followed by centrifugation at $1640 \mathrm{~g}$ for 15 minutes at $20^{\circ} \mathrm{C}$. The supernatant was then filtered and allowed to stand at room temperature for evaporation of solvent. The residue was then dissolved in distilled water to a volume of $20 \mathrm{ml}$.

Total phenolic content of the extracted juice were determined by the use of Folin-Ciocalteu reagent as per the method of Slinkard and Singleton (1977). The standard calibration curve was prepared by using Gallic acid as a standard. The result was expressed as milligrams per liter of Gallic acid equivalents (GAE) per 100 gm fresh weight.

\subsection{Statistical analysis}

Significant differences among different coatings, vibration, and days of storage on different quality parameters were analyzed with one-way ANOVAs. The coatings and vibration treatments were compared on the basis of fungal decay percentage, $\mathrm{pH}$, total polyphenol content, total soluble solids content and titratable acidity. The level of significance for all the analysis was chosen to be 0.05 . The means for different treatments were compared with least significant difference (LSD) test. All statistical analyses were performed using JMP software package for windows (JMP®, Version 12.2. SAS Institute Inc., Cary, NC, 2016).

\section{Result and Discussion}

\subsection{Fungal decay}

Due to their high physiological activities, strawberries are highly perishable fruits with a short shelf-life. From the observations made up to 14 days, fungal decay percentage was found to increase with the number of days of storage in each types of coatings and control. The effect of days of storage showed significant effect $(p<0.05)$ on fungal decay \% of strawberries. A gray mold, Botrytis cinerea, is the most predominant mold that causes decay of strawberries (Harvey and Pentzer 1960). The organism primarily infects the flower causing rot or remains dormant. The dormant mold shows its activity when the concentration of sugars increases and favorable 
environmental conditions are available either before or after harvesting of berries (Ayala-Zavala, Wang et al. 2004).

Among the two sets of coatings designed, in Set 1, i.e. set of curcumin treated strawberries, effect of vibration on fungal decay $\%$ was also found to be significant $(p=0.048)$. The vibrated curcumin treated strawberries were found to have significantly higher fungal decay (45.5\%) compared to the non- vibrated strawberries $(27.625 \%)$. This effect was more pronounced om the $14^{\text {th }}$ day of storage (Fig. 7). For all coating treatments, significant difference was not observed between vibrated and non-vibrated until the $9^{\text {th }}$ days of storage. However, from $9^{\text {th }}$ days onwards all the vibrated samples were found to have significantly higher mold growth. The difference in fungal decay $\%$ between vibrated and non-vibrated can be attributed to the change in integrity of coatings by the simulated vibration. Mechanical damage due to vibration contributes to a significant loss in perishable fruits and vegetables. In a study by Fischer et al. (1992), major damage of strawberries due to simulated in-transit vibration of 5.0 to $10 \mathrm{~Hz}$ was reported. Mechanical damages caused by vibrations can affect the integrity of plasma cells of skin and chemical contents of fruits resulting in change in bloom and tissue softening of fruits (Zhou, Su et al. 2007).

Among the berries coated with phytochemicals, curcumin coatings showed significantly lower fungal decay percentage compared to control and limonene coatings up to $2^{\text {nd }}$ day of storage (Fig. 2a). However, there was no significant difference in the fungal decay $\%$ after the $2^{\text {nd }}$ day of storage. Curcumin coatings showed a lower fungal decay at the $14^{\text {th }}$ day of storage (Fig. 2a), which was found to be significant compared to control. Fungal decay \% among the treatment formulations containing MC had higher mean value (40.78\%) as compared with control samples (36.41\%) (Fig. 2b) which is in agreement with the study conducted by Perdones et al. (2016). The bilayer coating of phytochemicals and MC did not show any significant reductions in fungal decay percentage compared to control (Fig. 2c).

Liposome coated samples exhibited an elongated preservation effects, supported by significantly lower visual mold growth compared to control during the $14^{\text {th }}$ day of storage onwards (Fig. $2 \mathrm{~d}$ ). Curcumin liposome coated samples exhibited significant reduction in fungal decay in $2^{\text {nd }}, 5^{\text {th }}$ and $14^{\text {th }}$ days of storage compared to control (Fig. 2d). Meanwhile, on the $14^{\text {th }}$ day of storage, limonene liposome coated samples were found to be significantly $(p=0.0247$ ) effective in 
controlling fungal decay compared to control (Fig. 2d). This indicates that, for further extension of shelf life, it is suggested to study the effects of liposome coatings.

\subsection{TSS}

Total soluble solid was found to be significantly higher in the Set 2 limonene treated strawberries as compared to the Set 1 curcumin treated strawberries $(p=0.0301)$. Days of storage also showed significant effect ( $p=0.0239$ ) on the TSS on each set of coatings designed (Fig. 3). No significant difference in TSS was observed between vibrated and non-vibrated strawberry samples. It was observed that there was an increase in TSS with days of storage. The change in TSS content might be due to the solubilization of the cell wall polyuronides and hemicelluloses in mature strawberries (Hernandez-Munoz, Almenar et al. 2008). TSS values of strawberries generally ranges from 7-12\% depending upon the genotypic characteristic of the fruit (Galletta, Maas et al. 1995). High TSS values are generally accompanied by good flavor of strawberries (Kader 1991).

\section{3. $\mathrm{pH}$}

The limonene coated sample set was found to have significantly higher $\mathrm{pH}$ than curcumin coated samples $(\mathrm{p}<0.0001)$ and the control $(p=0.0132)$ (Fig. 4). The days of storage was shown to have significant effect $(p<0.05)$ on the $\mathrm{pH}$ among the curcumin treated strawberries whereas the effect was not apparent among the limonene treated and control strawberries. The $\mathrm{pH}$ of limonene coated berries, decreased up to 5 days of storage but there is no significant increase on

the $14^{\text {th }}$ day. The obtained results are in agreement with similar research conducted by Montero (1996) who observed initial decreases followed by increases of $\mathrm{pH}$ during storage of strawberries. For both vibrated and non-vibrated curcumin coated and control berries, the $\mathrm{pH}$ increased throughout storage. However, there was no difference in $\mathrm{pH}$ among vibrated and nonvibrated samples.

A similar study conducted by Zheng et al. (2007) found an increase in $\mathrm{pH}$ during storage, which can be related to effects of increased $\mathrm{O}_{2}$ on the respiration rate of fruits.

\subsection{Titratable acidity (TA)}

Days of storage was shown to have significant effect $(p=0.0284)$ on TA content among the set of both vibrated and non-vibrated limonene coated strawberries. There was an increasing trend 
observed up to the $9^{\text {th }}$ day of storage, and a non-significant decrease in the value at 14 days of storage. No pronounced effect was observed in TA among the set of both vibrated and nonvibrated curcumin coated and control strawberries. Titratable acidity content was found to be significantly higher $(p<0.0001)$ in limonene as compared to curcumin treated strawberries (Fig. 5). This observation indicates a decrease in the fruit respiration metabolism resulting an increase in the TA (de Oliveira, Magnani et al. 2014). TA is defined as the percentage of citric acid per strawberry wet weight. The differences in TA content observed between the curcumin coated and uncoated samples compared with limonene coated samples can be attributed to the increased water loss (Hernandez-Munoz, Almenar et al. 2008). Decreased TA content can be related to the decline in the organoleptic quality of the strawberries (Yang, Li et al. 2010).

\subsection{Total Phenolic Content (TPC)}

Limonene coated strawberries were found to have significantly higher ( $p=0.0023) \mathrm{TPC}$ as compared to curcumin coated and control samples (Fig 6). There was an increasing trend in the TPC content of the limonene coated berries up to 14 days of storage. The change in the concentrations of phenolic compounds in fruits during storage can be attributed to cell structure breakdown (Macheix and Fleuriet 1990). Meanwhile, in curcumin coated and control samples, there was no significant increase in the TPC content from $2^{\text {nd }}$ day to $5^{\text {th }}$ day of storage, however significant increase was observed $5^{\text {nd }}$ to $9^{\text {th }}$ days of storage (Fig 6). The days of storage was found to have a significant effect $(p<0.0001)$ on TPC content of curcumin treated strawberries whereas the effect was not seen in limonene treated strawberries. These observations concurred with the findings by Ayala-Zavala et al. (2004).

\section{Conclusion}

In summary, the results obtained in this paper indicate that storage time significantly affects the quality parameters of coated and non-coated strawberries. Vibration was also found to have a significant effect on fungal decay and total soluble solids among all the coating treatments. Among different coating types, liposomes were found to be the most effective for the preservation of strawberry quality and the limonene liposome was found to be effective in controlling fungal decay on strawberries for a prolonged period of storage. Similarly, titratable 
acidity and total phenolic contents were also found to be higher in limonene coated strawberries compared to other coatings.

\section{Acknowledgement}

Partial funding for this project came from Research Grant No. US-4680-13C from BARD The United States - Israel Binational Agricultural Research and Development Fund; USDA-NIFA Food Safety Outreach grant; National Institutes of Health; and the Elevating Research grant from SIU, Carbondale, IL. April Vigardt provided trucks to measure vibrations during local produce transportation, and Derek J. Fisher provide critical review of the manuscript.

\section{REFERENCES:}

Ayala-Zavala, J. F., Wang, S. Y., Wang, C. Y., \& Gonzalez-Aguilar, G. A. (2004). Effect of storage temperatures on antioxidant capacity and aroma compounds in strawberry fruit. Lebensmittel-Wissenschaft Und-Technologie-Food Science and Technology, 37, 687-695.

Bangham, A. D. (1961). A Correlation between Surface Charge and Coagulant Action of Phospholipids. Nature, 192, 1197-\&.

Barchi, G., Berardinelli, A., Guarnieri, A., Ragni, L., \& Fila, C. T. (2002). PH—postharvest technology: damage to loquats by vibration-simulating intra-state transport. Biosystems Engineering, 82, 305-312.

Brandl, M. (2001). Liposomes as drug carriers: a technological approach. Biotechnology annual review, 7, 59-85.

de Oliveira, C. E. V., Magnani, M., de Sales, C. V., de Souza Pontes, A. L., Campos-Takaki, G. M., Stamford, T. C. M., \& de Souza, E. L. (2014). Effects of chitosan from Cunninghamella elegans on virulence of post-harvest pathogenic fungi in table grapes (Vitis labrusca L.). International journal of food microbiology 171: 54-61.

Debeaufort, F., Quezada-Gallo, J. A., \& Voilley, A. (1998). Edible films and coatings: tomorrow's packagings: a review. Crit Rev Food Sci Nutr, 38, 299-313.

Dogra, N., Choudhary, R., Kohli, P., Haddock, J. D., Makwana, S., Horev, B., Vinokur, Y., Droby, S., \& Rodov, V. (2015). Polydiacetylene Nanovesicles as Carriers of Natural Phenylpropanoids for Creating Antimicrobial Food-Contact Surfaces. Journal of Agricultural and Food Chemistry, 63, 2557-2565.

EPA, U. (1994). Reregistration Eligibility Decision (RED) Limonene. (EPA 738-R-94-034). Washington, DC, USA.

Fischer, D., Craig, W., Watada, A., Douglas, W., \& Ashby, B. (1992). Simulated in-transit vibration damage to packaged fresh market grapes and strawberries. Applied engineering in agriculture, 8, 363-366. 
Galletta, G., Maas, J., Enns, J., Draper, A., Dale, A., \& Swartz, H. (1995). Mohawk'strawberry. HortScience, 30, 631-634.

Hagenmaier, R. D. (2002). The flavor of mandarin hybrids with different coatings. Postharvest Biology and Technology, 24, 79-87.

Han, Y., \& Nie, L. (2004). The mechanism of protecting fresh and preparation of nano TiO2 thin film. Journal of Zhuzhou Institute of Technology, 18, 148-150.

Harvey, J. M., \& Pentzer, W. T. (1960). Market diseases of Grapes and other small fruits. Market diseases of Grapes and other small fruits.

Heinonen, I. M., Meyer, A. S., \& Frankel, E. N. (1998). Antioxidant activity of berry phenolics on human low-density lipoprotein and liposome oxidation. Journal of Agricultural and Food Chemistry, 46, 4107-4112.

Hernandez-Munoz, P., Almenar, E., Del Valle, V., Velez, D., \& Gavara, R. (2008). Effect of chitosan coating combined with postharvest calcium treatment on strawberry (Fragariax ananassa) quality during refrigerated storage. Food chemistry, 110, 428-435.

Hernandez-Munoz, P., Almenar, E., Ocio, M. J., \& Gavara, R. (2006). Effect of calcium dips and chitosan coatings on postharvest life of strawberries (Fragaria $\mathrm{x}$ ananassa). Postharvest Biology and Technology, 39, 247-253.

Holcroft, D. M., \& Kader, A. A. (1999). Carbon dioxide-induced changes in color and anthocyanin synthesis of stored strawberry fruit. HortScience, 34, 1244-1248.

Hu, L.Y., Hu, S., Wu, J., Li, Y., Zheng, J., Wei, Z., Liu, J., Wang, H., Liu, Y., \& Zhang, H. (2012). Hydrogen sulfide prolongs postharvest shelf life of strawberry and plays an antioxidative role in fruits. Journal of agricultural and food chemistry 60, 35, 8684-8693.

Huang, Y.-y., \& Hu, Q.-h. (2006). Effect of a New Fashion Nano-packing on Preservation Quality of Green Tea [J]. Food Science, 4, 061.

Kader, A. A. (1991). Quality and its maintenance in relation to the postharvest physiology of strawberry. The strawberry into the 21st century. Timber Press, Portland, OR145-152.

Ke, D. Y., Zhou, L. L., \& Kader, A. A. (1994). Mode of Oxygen and Carbon-Dioxide Action on Strawberry Ester Biosynthesis. Journal of the American Society for Horticultural Science, 119, 971-975.

Lacroix, M. (2007). The Use of Essential oils and bacteriocins as natural antimicrobial and antioxidant compounds. Food, 1, 181-192.

Li, H. M., Li, F., Wang, L., Sheng, J. C., Xin, Z. H., Zhao, L. Y., Xiao, H. M., Zheng, Y. H., \& $\mathrm{Hu}, \mathrm{Q}$. H. (2009). Effect of nano-packing on preservation quality of Chinese jujube (Ziziphus jujuba Mill. var. inermis (Bunge) Rehd). Food chemistry, 114, 547-552.

Li, Z., \& Wang, M. (2006). Research on nano-SiOx/chitosan keeping fresh agents and applications to Fuji apples. Journal of Guizhou University of Technology, 35, 99-102.

Macheix, J. J., \& Fleuriet, A. (1990). Fruit phenolics. CRC press.

Maheshwari, R. K., Singh, A. K., Gaddipati, J., \& Srimal, R. C. (2006). Multiple biological activities of curcumin: a short review. Life Sci, 78, 2081-2087.

Makwana, S., Choudhary, R., \& Kohli, P. (2015). Advances in Antimicrobial Food Packaging with Nanotechnology and Natural Antimicrobials. International Journal of Food Science and Nutrition Engineering, 5, 169-175.

Manning, K. (1993). Biochemistry of fruit ripening. In G. Seymour, J. Taylor \& G. Tucker (Eds.), Biochemistry of fruit ripening (1 ed.).

Michael, J. P. (2004). Nanomaterials-the driving force. Materials Today, 7, 20-29. 
Montero, T. M., Mollá, E. M., Esteban, R. M., \& López-Andréu, F. J. (1996). Quality attributes of strawberry during ripening. Scientia Horticulturae, 65, 239-250.

Moufida, S., \& Marzouk, B. (2003). Biochemical characterization of blood orange, sweet orange, lemon, bergamot and bitter orange. Phytochemistry, 62, 1283-1289.

Pavlath, A. E., \& Orts, W. (2009). Edible Films and Coatings: Why, What, and How? 1-23.

Perdones, A., Escriche, I., Chiralt, A., \& Vargas, M. (2016). Effect of chitosan-lemon essential oil coatings on volatile profile of strawberries during storage. Food chemistry, 197, 979986.

Perdones, Á., Tur, N., Chiralt, A., \& Vargas, M. (2016). Effect on tomato plant and fruit of the application of biopolymer-oregano essential oil coatings. Journal of the Science of Food and Agriculture.

Perez- Gago, M., Rojas, C., \& DelRio, M. (2002). Effect of Lipid Type and Amount of Edible Hydroxypropyl Methylcellulose- lipid Composite Coatings Used to Protect Postharvest Quality of Mandarins cv. Fortune. Journal of food science, 67, 2903-2910.

Pierson, T. R., Allen, J. W., \& McLaughlin, E. W. (1982). Produce losses in the US food distribution system: Department of Agricultural Economics, Michigan State University.

Pineli, L. D. L. D. O., Moretti, C. L., dos Santos, M. S., Campos, A. B., Brasileiro, A. V., Córdova, A. C., \& Chiarello, M. D. (2011). Antioxidants and other chemical and physical characteristics of two strawberry cultivars at different ripeness stages. Journal of Food Composition and Analysis, 24,1, 11-16.

Raghav, P.K., Agarwal, N., \& Saini, M. (2016). Edible coating of fruits and vegetables: A review. International Journal of Scientific Research and Modern Education, 1 (1), 188204.

Rice-Evans, C., \& Miller, N. (1996). Antioxidant activities of flavonoids as bioactive components of food. Biochemical Society Transactions, 24, 790-795.

Rodriguez, A., Batlle, R., \& Nerin C. (2007). The use of natural essential oils as antimicrobial solutions in paper packaging. Part II. Progress in Organic Coatings, 60, 33-38.

Salmieri, S., \& Lacroix, M. (2006). Physicochemical properties of alginate/polycaprolactonebased films containing essential oils. Journal of Agricultural and Food Chemistry, 54, 10205-10214.

Sanchez-Gonzalez, L., Chafer, M., Hernandez, M., Chiralt, A., \& Gonzalez-Martinez, C. (2011). Antimicrobial activity of polysaccharide films containing essential oils. Food Control, $22,1302-1310$.

Sharma, N., \& Tripathi, A. (2008). Effects of Citrus sinensis (L.) Osbeck epicarp essential oil on growth and morphogenesis of Aspergillus niger (L.) Van Tieghem. Microbiological Research, 163, 337-344.

Shin, G. H., Chung, S. K., Kim, J. T., Joung, H. J., \& Park, H. J. (2013). Preparation of ChitosanCoated Nanoliposomes for Improving the Mucoadhesive Property of Curcumin Using the Ethanol Injection Method. Journal of Agricultural and Food Chemistry, 61, 1111911126.

Slinkard, K., \& Singleton, V. L. (1977). Total Phenol Analysis - Automation and Comparison with Manual Methods. American Journal of Enology and Viticulture, 28, 49-55.

Valencia-Chamorro, S. A., Perez-Gago, M. B., Del Rio, M. A., \& Palou, L. (2010). Effect of antifungal hydroxypropyl methylcellulose-lipid edible composite coatings on Penicillium 
decay development and postharvest quality of cold-stored "Ortanique" mandarins. Journal offood science, 75, S418-426.

Wang, K., Liang, S., Du, R. N., Zhang, Q., \& Fu, Q. (2004). The interplay of thermodynamics and shear on the dispersion of polymer nanocomposite. Polymer, 45, 7953-7960.

Wozniak, W., Radajewska, B., Reszelska-Sieciechowicz, A., \& Dejwor, I. (1996). Sugars and acid content influence organoleptic evaluation of fruits of six strawberry cultivars from controlled cultivation. In III International Strawberry Symposium 439, 333-336

Yang, F., Li, H., Li, F., Xin, Z., Zhao, L., Zheng, Y., \& Hu, Q. (2010). Effect of Nano- Packing on Preservation Quality of Fresh Strawberry (Fragaria ananassa Duch. cv Fengxiang) during Storage at $4^{\circ}$ C. Journal of food science, 75, C236-C240.

Zheng, Y., Wang, S. Y., Wang, C. Y., \& Zheng, W. (2007). Changes in strawberry phenolics, anthocyanins, and antioxidant capacity in response to high oxygen treatments. LWT-Food Science and Technology, 40, 49-57.

Zhou, R., Su, S. Q., Yan, L. P., \& Li, Y. F. (2007). Effect of transport vibration levels on mechanical damage and physiological responses of Huanghua pears (Pyrus pyrifolia Nakai, cv. Huanghua). Postharvest Biology and Technology, 46, 20-28. 


\section{Figure Caption:}

Figure 1. Experimental setup showing clamshell containing strawberry placed on the vibration test apparatus

Figure 2a: Fungal decay \% varying with the days of storage among the phytochemical treatments only. Error bars represent \pm Standard Error

Figure 2 b. Fungal decay $\%$ varying with the days of storage among the strawberries coated with methyl cellulose (MC) compared to control. Error bars represent \pm Standard Error

Figure $2 \mathrm{c}$. Fungal decay $\%$ varying with the days of storage among the coating treatments mixed with methyl cellulose (MC). Error bars represent \pm Standard Error

Figure $2 \mathrm{~d}$. Fungal decay $\%$ varying with the days of storage among the liposome coating treatments compared to control. Error bars represent \pm Standard Error

Figure 3. Mean total soluble solids for two sets of coatings. Error bars represent \pm Standard Error

Figure 4: Mean $\mathrm{pH}$ for two set of coatings. Error bars represent \pm Standard error

Figure 5. Mean titratable acidity for two sets of coatings. Error bars represent \pm Standard Error

Figure 6. Mean total phenolic content for two set of coatings. Error bars represent \pm Standard Error

Figure 7. Fungal decay percentage among vibrated and non-vibrated samples. Error bars represent \pm Standard Error

Figure 8. Flowchart representing steps in preparation of coating materials

Figure 9. Pictorial representation of liposome preparation 


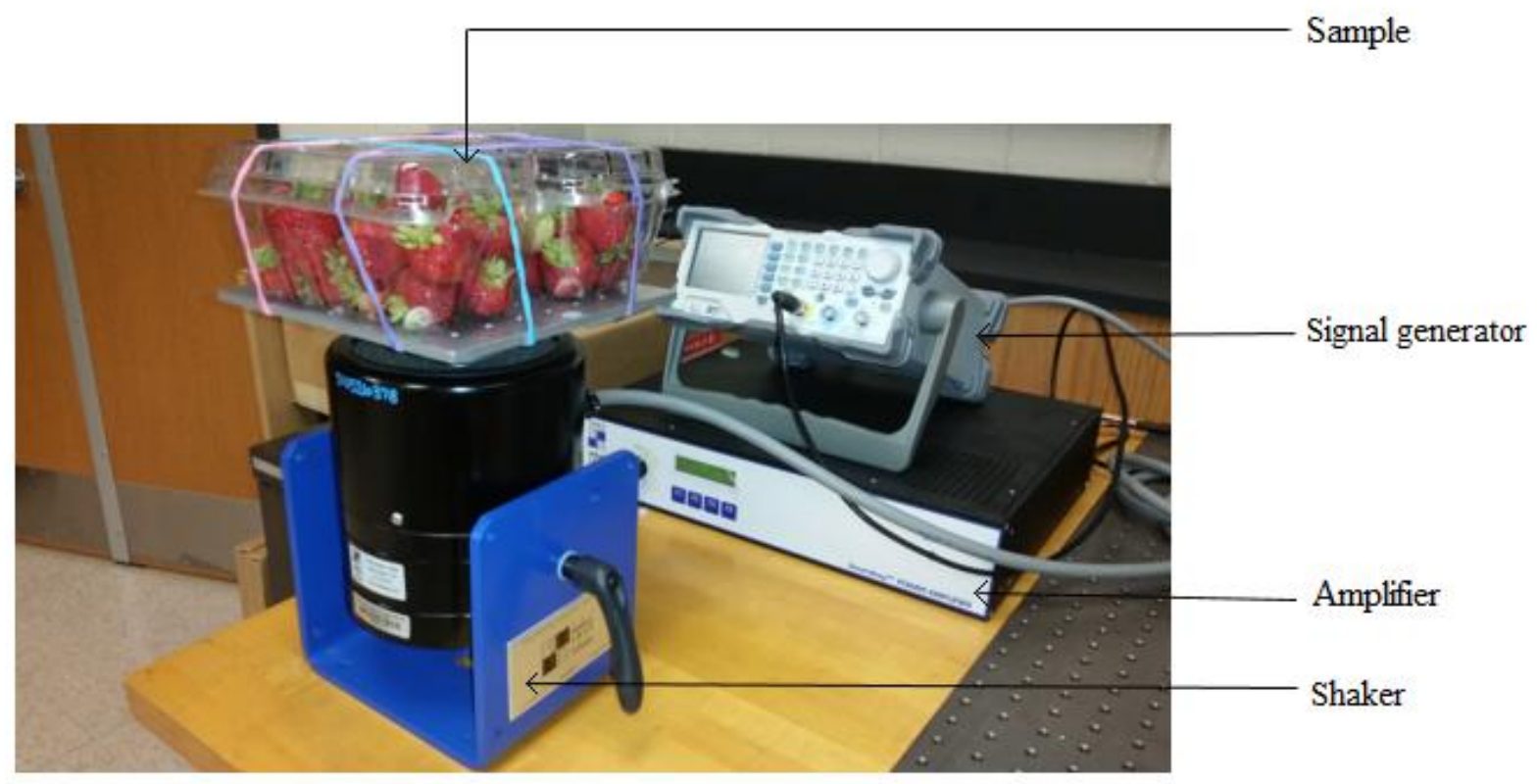

Figure 1. Experimental setup showing clamshell containing strawberry placed on the vibration test apparatus. 


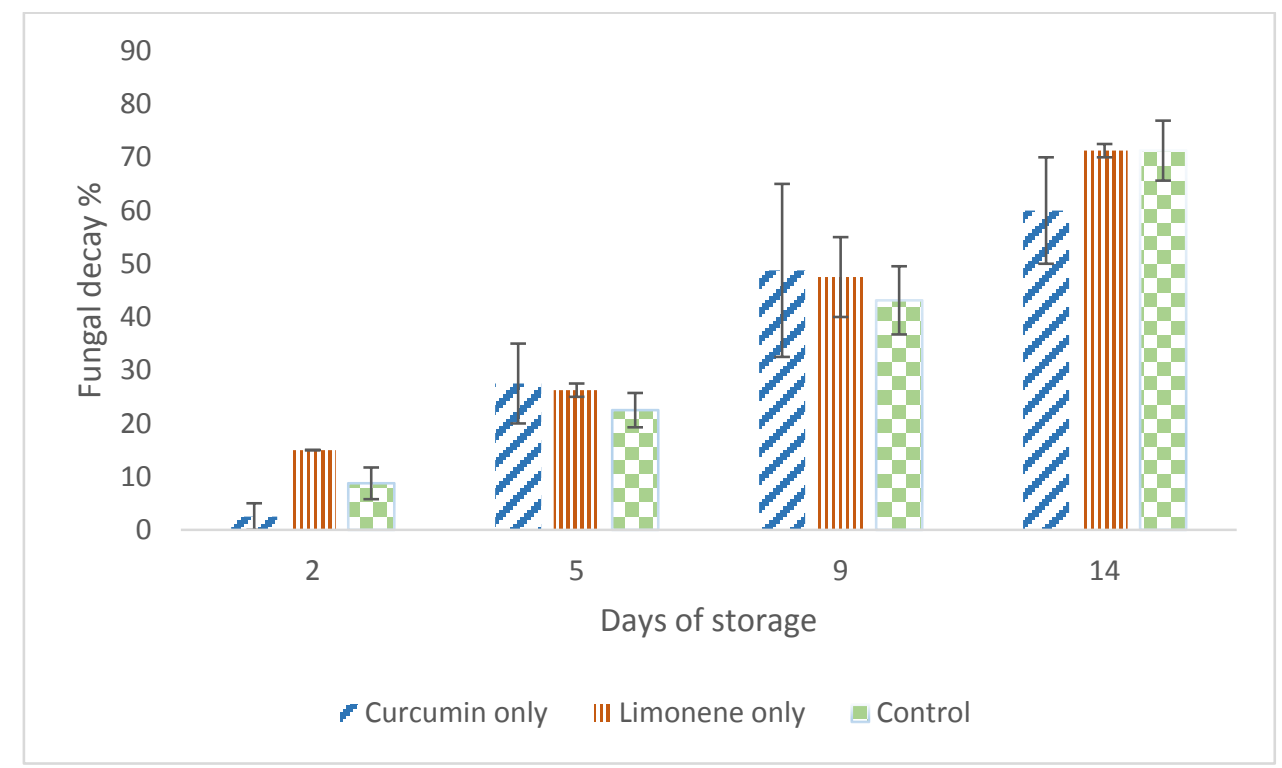

Figure $2 \mathrm{a}$. Fungal decay $\%$ varying with the days of storage among the phytochemical treatments only. Error bars represent \pm Standard Error 


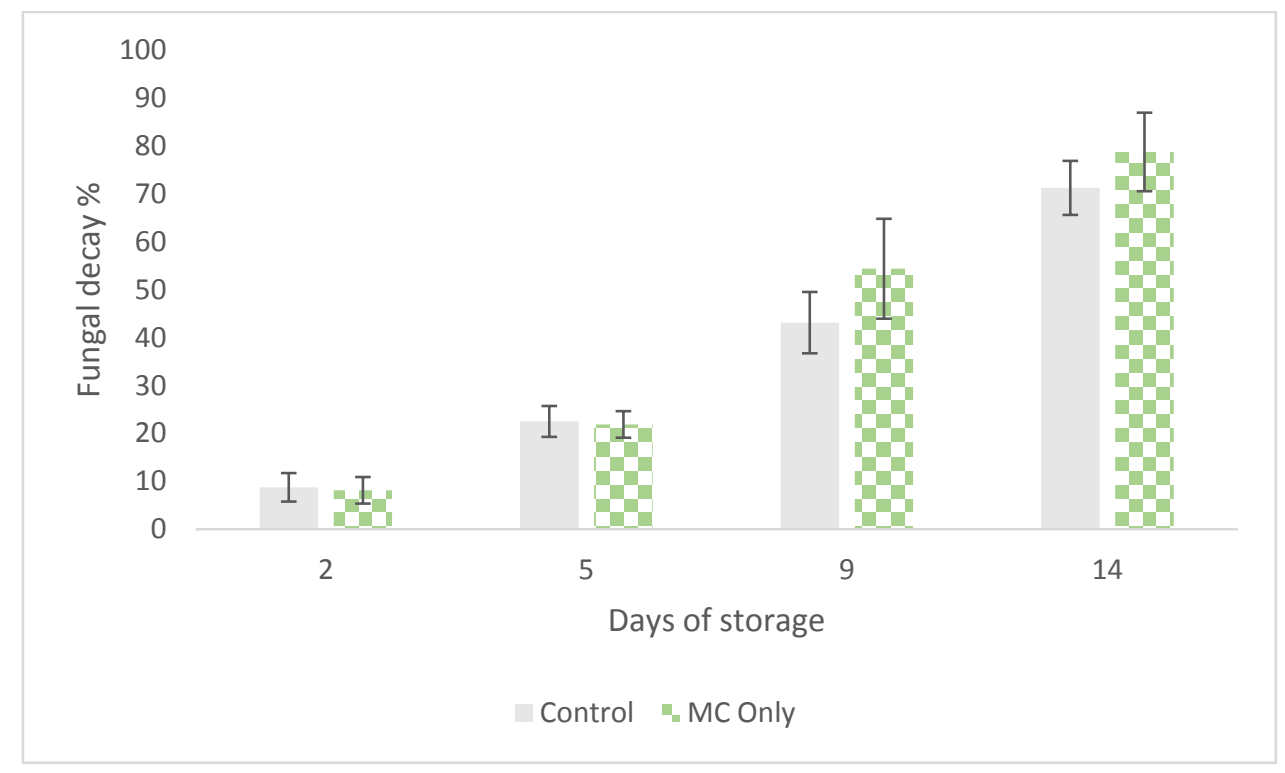

Figure $2 \mathrm{~b}$. Fungal decay $\%$ varying with the days of storage among the strawberries coated with methyl cellulose (MC) compared to control. Error bars represent \pm Standard Error 


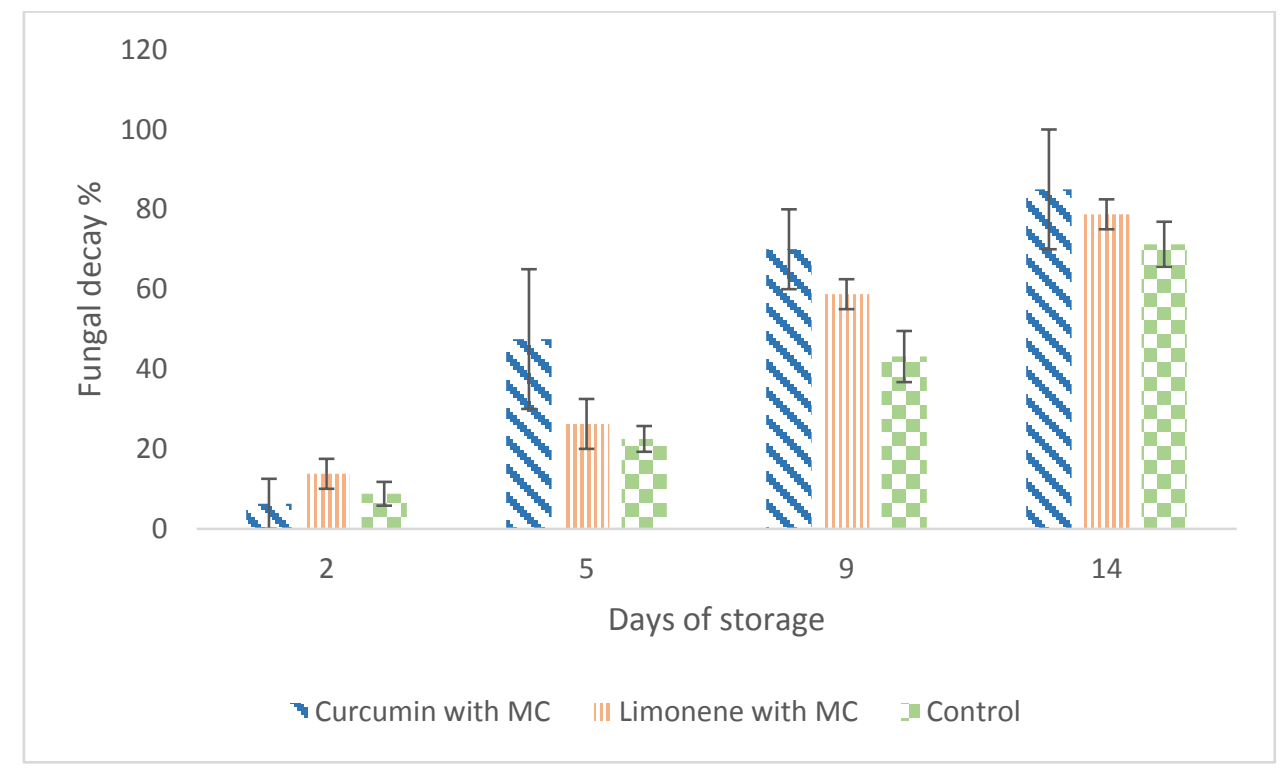

Figure $2 \mathrm{c}$. Fungal decay $\%$ varying with the days of storage among the coating treatments mixed with methyl cellulose (MC). Error bars represent \pm Standard Error 


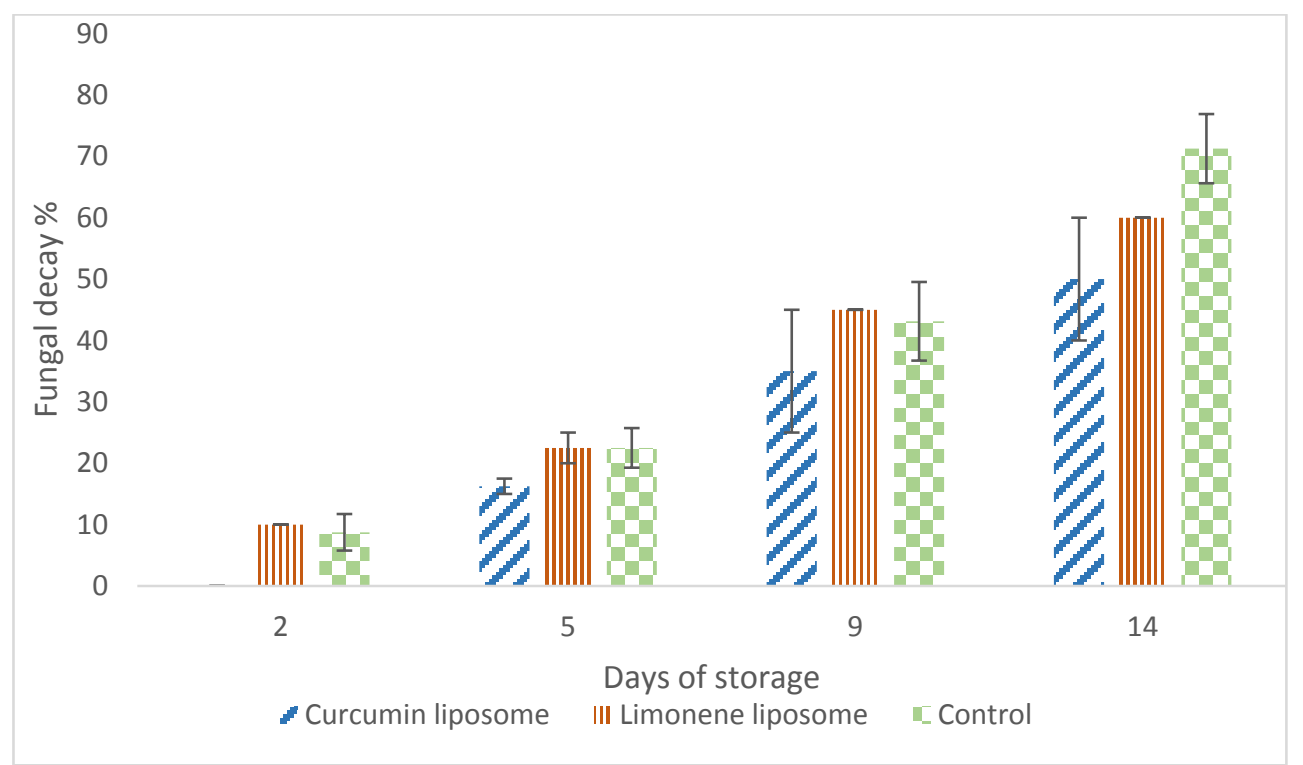

Figure $2 \mathrm{~d}$. Fungal decay $\%$ varying with the days of storage among the liposome coating treatments compared to control. Error bars represent \pm Standard Error 


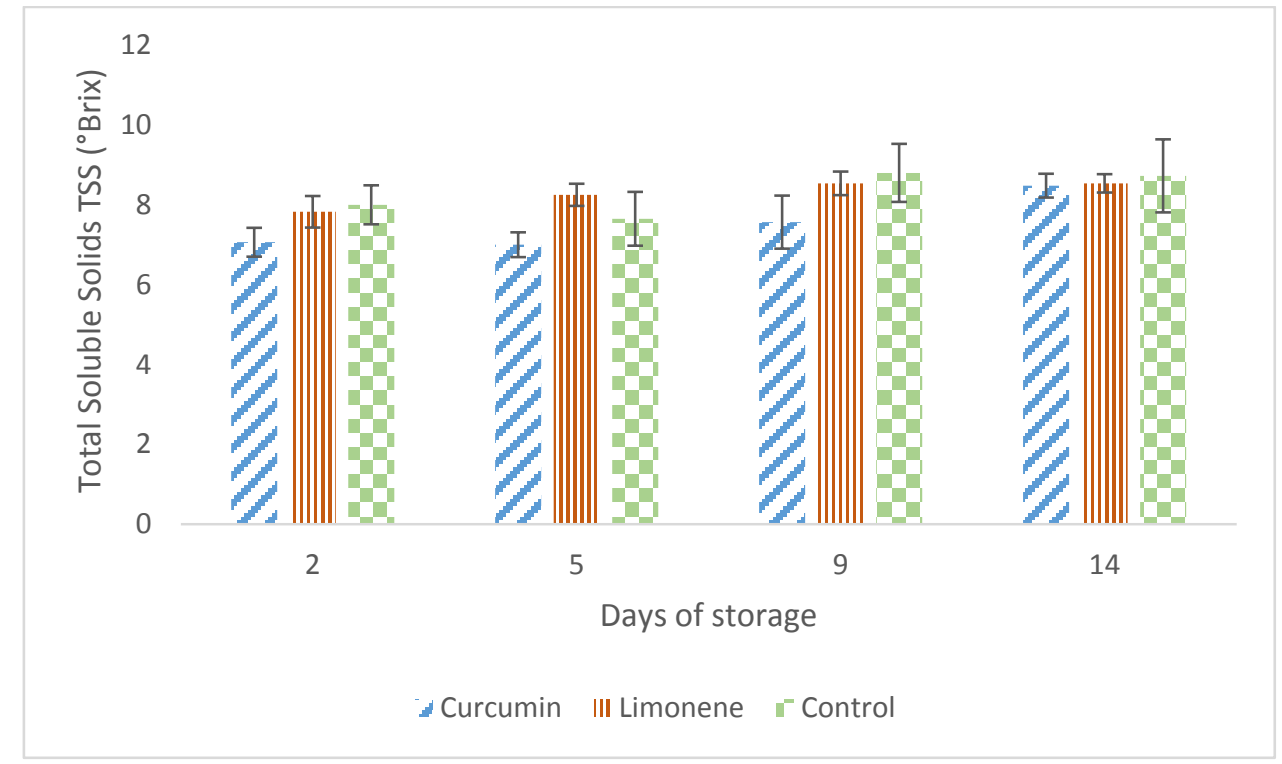

Figure 3. Mean total soluble solids for two sets of coatings. Error bars represent \pm Standard Error 


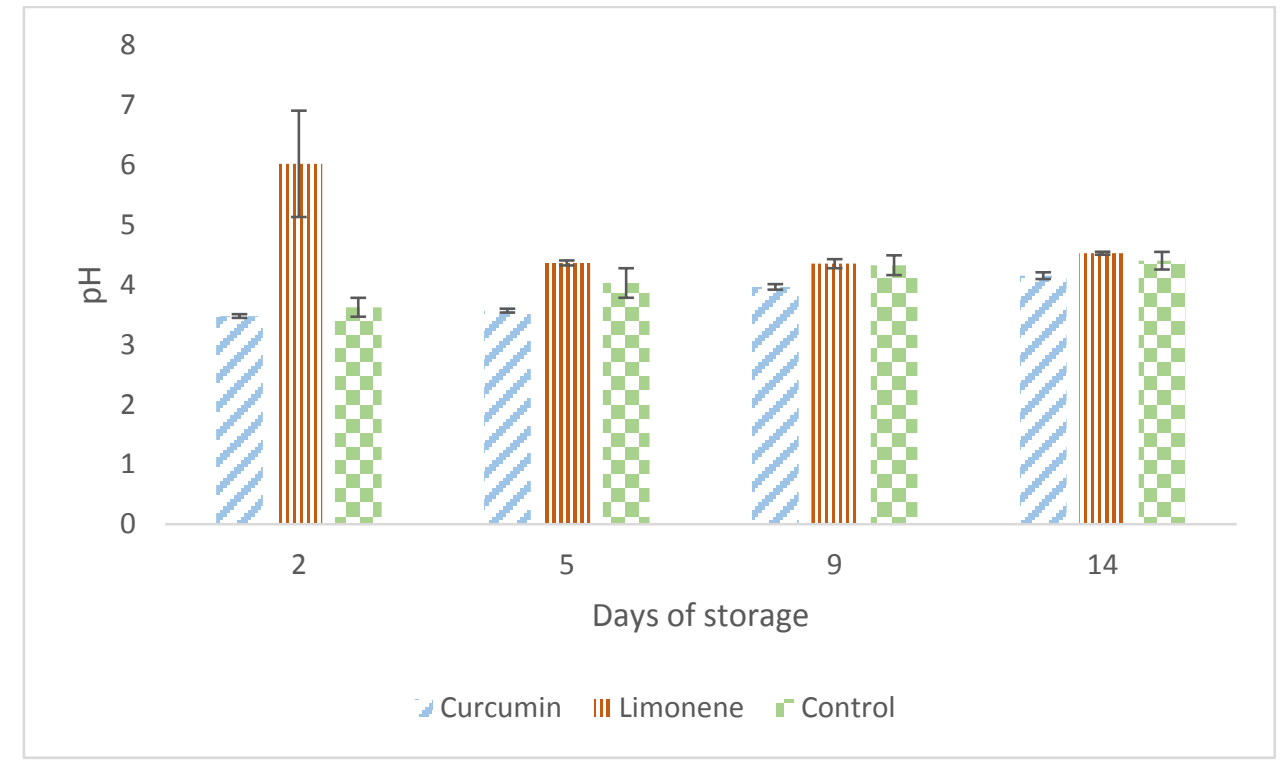

Figure 4. Mean $\mathrm{pH}$ for two set of coatings. Error bars represent \pm Standard error 


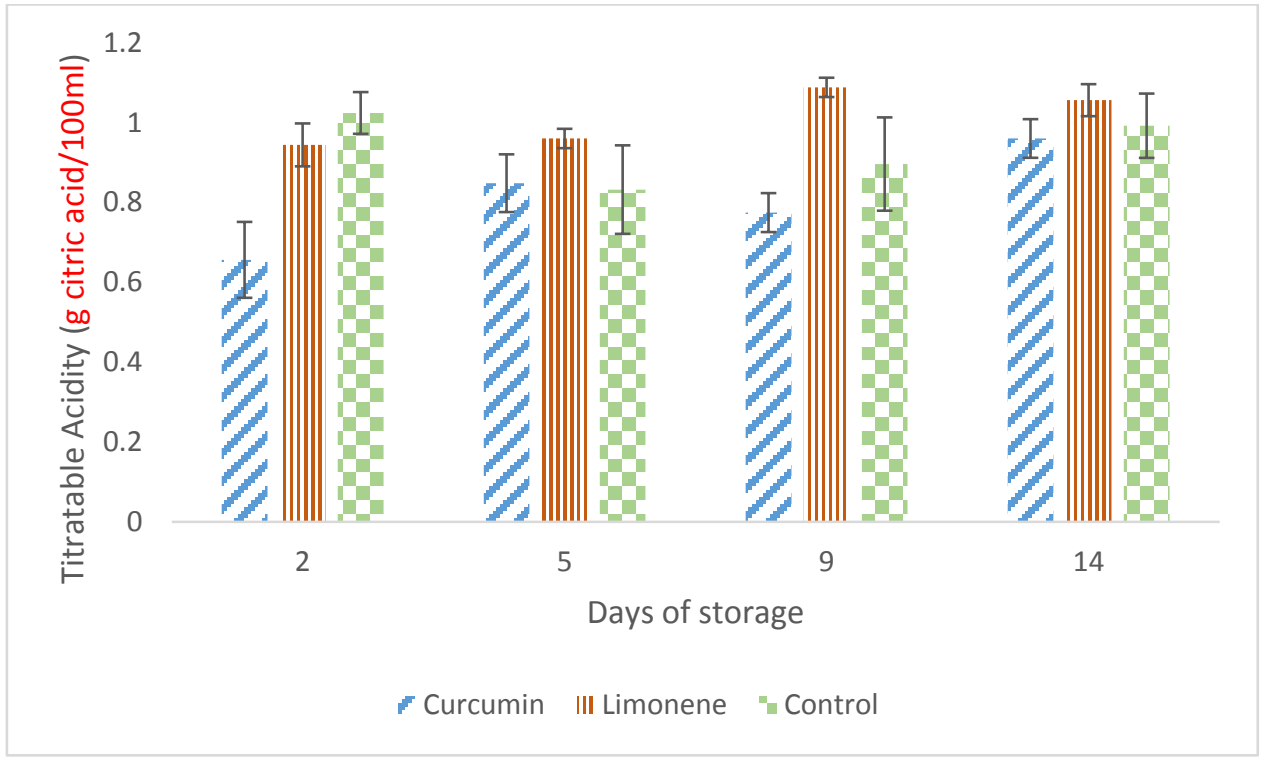

Figure 5. Mean titratable acidity for two sets of coatings. Error bars represent \pm Standard Error 


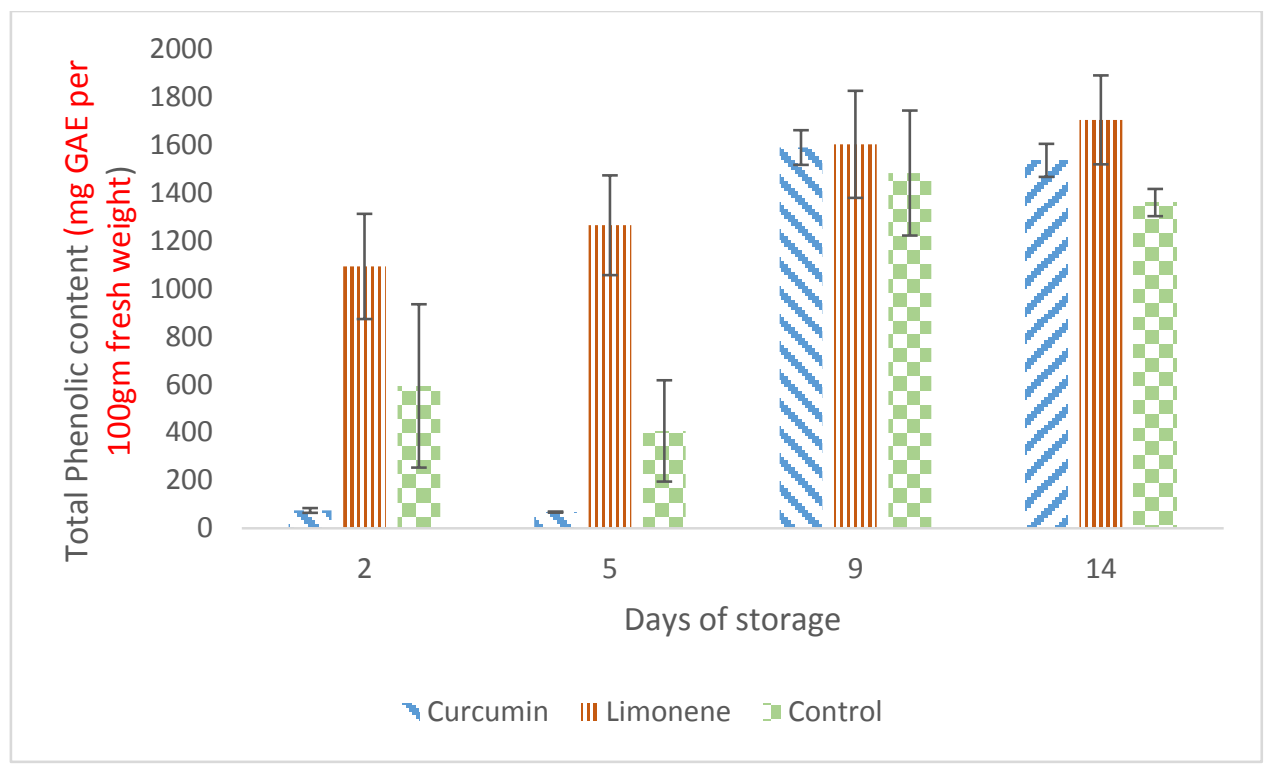

Figure 6. Mean total phenolic content for two set of coatings. Error bars represent \pm Standard Error

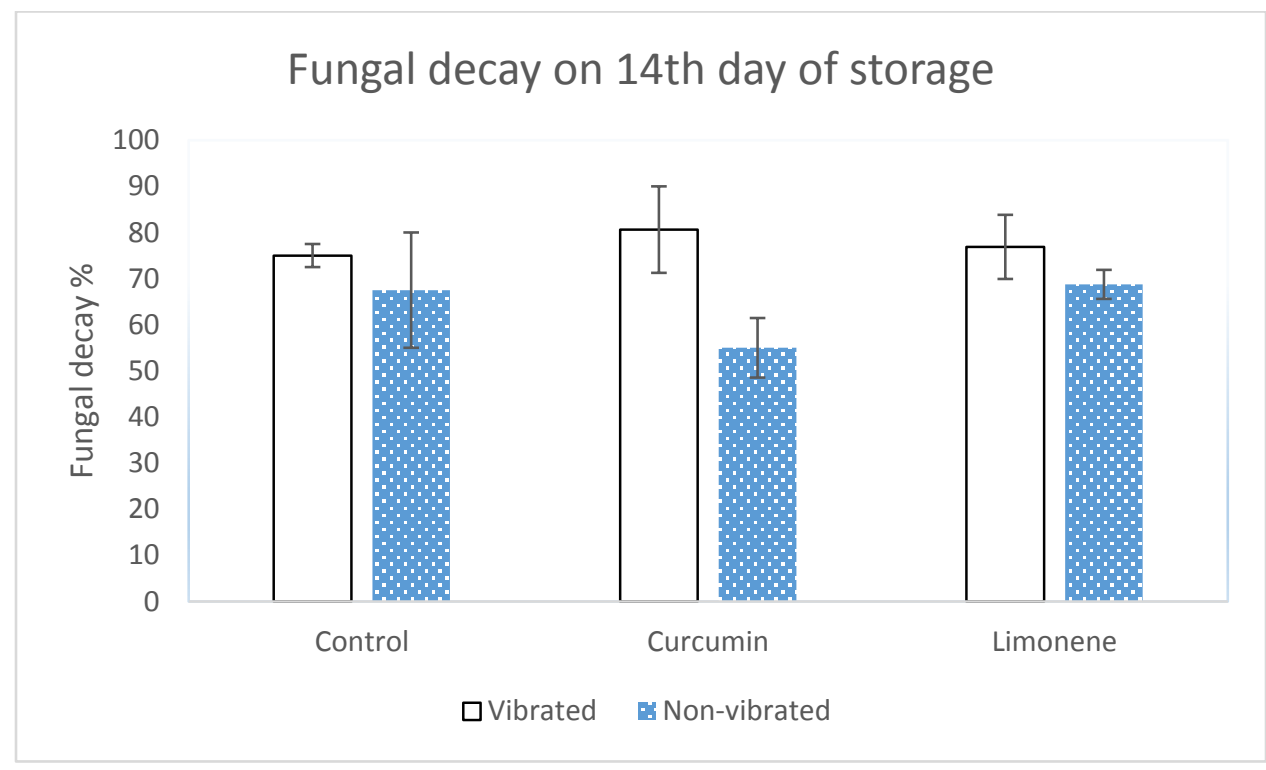

Figure 7. Fungal decay percentage among vibrated and non-vibrated samples. Error bars represent \pm Standard Error 


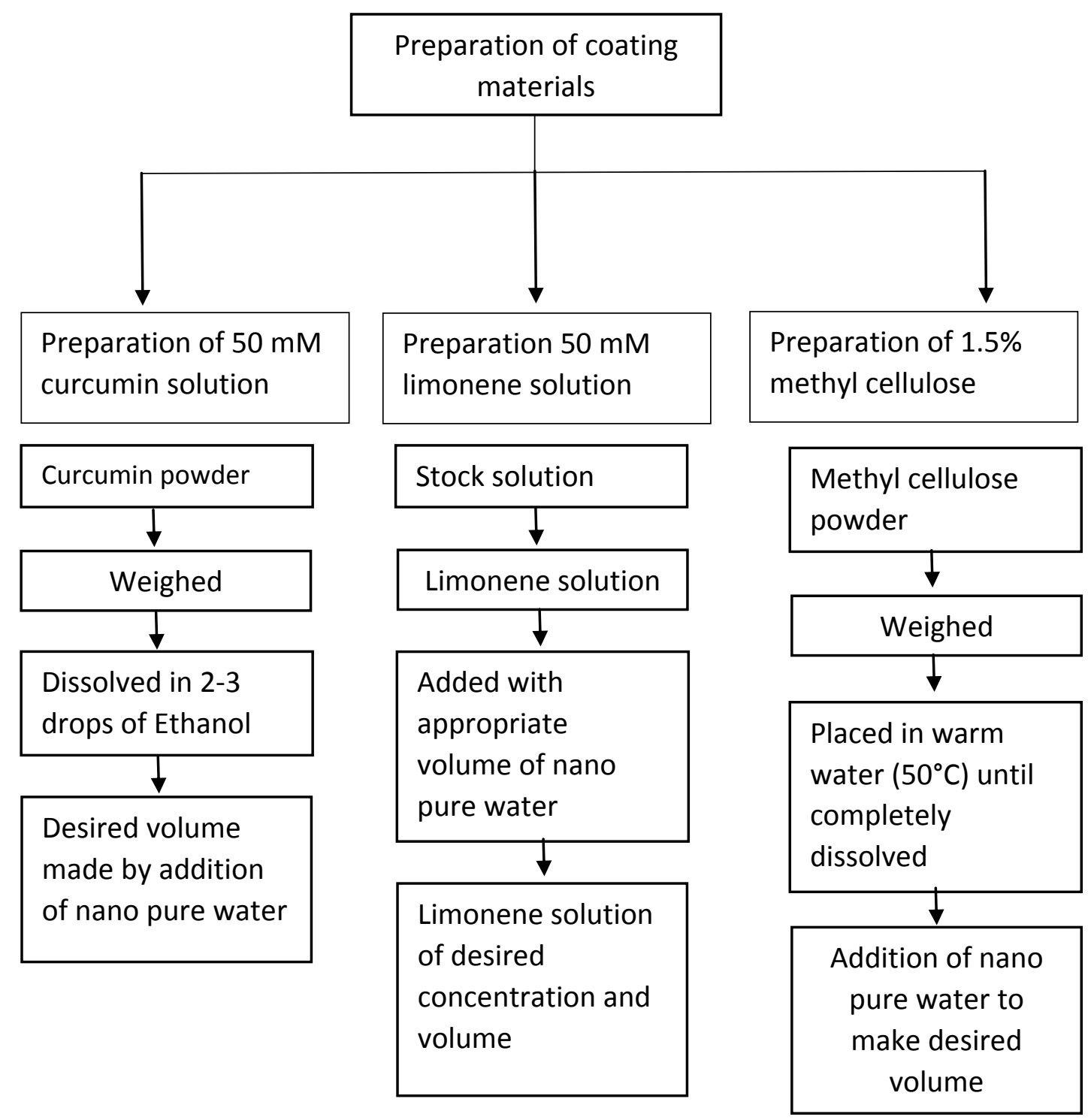

Figure 8. Flowchart representing steps in preparation of coating materials 


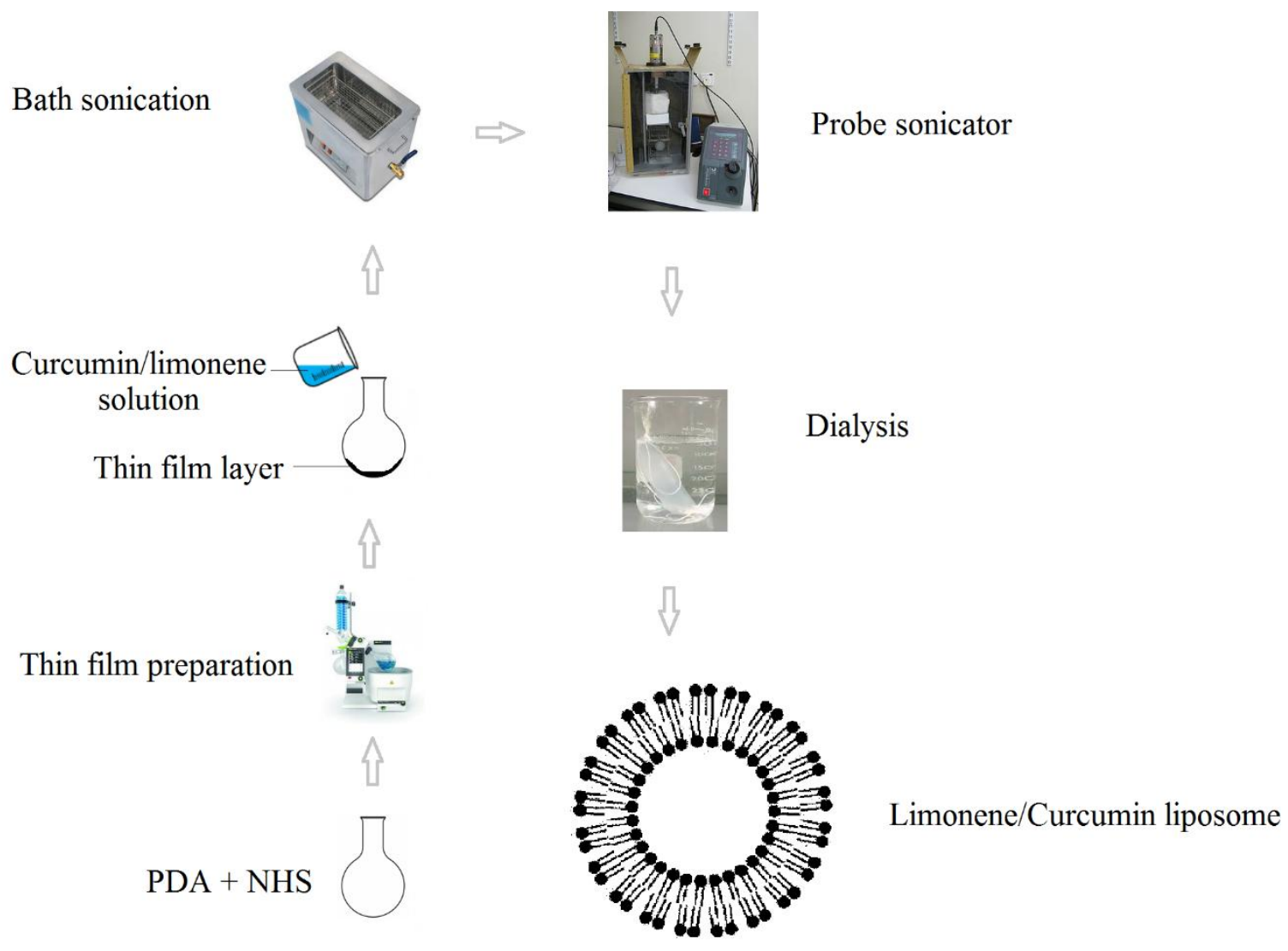

Figure 9. Pictorial representation of liposome preparation 